\title{
Comparison of Vitamin E and L-Carnitine, Separately or in Combination in Patients With Intradialytic Complications
}

\author{
Hamid Tayebi Khosroshahi ${ }^{1}$, Bohlul Habibi Asl ${ }^{2}$, Afshin Habibzadeh ${ }^{3,{ }^{*}}$, Parastoo Chaichi ${ }^{4}$, \\ Amin Ghanbarpour ${ }^{3}$, Amir Hossein Badie ${ }^{4}$ \\ ${ }_{2}^{1}$ Department of Nephrology, Liver and Gastrointestinal Disease Research Center, Tabriz University of Medical Sciences, Tabriz, IR Iran \\ 2 Department of Pharmacology, Tabriz University of Medical Sciences, Tabriz, IR Iran \\ 3 Department of Cardiology, Cardiovascular Research Center, Tabriz University of Medical Sciences, Tabriz, IR Iran \\ ${ }^{4}$ Medical Philosophy and History Research Center, Tabriz University of Medical Sciences, Tabriz, IR Iran \\ *Corresponding author: Afshin Habibzadeh, Cardiovascular Research Center, Tabriz University of Medical Sciences, Golbad Ave., Zip code: 5166618573, Tabriz, IR Iran. Tel: +98- \\ 9141404177, Fax: +98-4113344021, E-mail: Afshin.habibzadeh@gmail.com.
}

Received: February 10, 2013; Revised: February 24, 2013; Accepted: March 03, 2013

Background:The most common complications during dialysis are hypotension and muscle cramps. Thereare many strategies to prevent and treat these complications.

Objectives: The aim of this study is to evaluate effects of vitamin E and L-carnitine supplementation alone and in combination on intradialytic complications.

Patients and Methods: In a prospective study, 20 patients with end stage renal disease on chronic hemodialysis that had intradialytic complications such as hypotension, muscle cramp, nausea, vomiting and headache were studied. These patients were studied in four 45 day periods, beginning with no treatment(step1), receiving vitamin $\mathrm{E}(200 \mathrm{IU} / \mathrm{d})(\mathrm{step} 2)$, receiving L-carnitine (500 $\mathrm{mg} / \mathrm{d}$ )(step 3) and their combination (step 4). Intradialytic complications were recorded in each step and compared between treatments.

Results: All three treatments significantly reduced frequency of muscle cramps in comparison to baseline values. Vitamin $\mathrm{E}$ alone and in combination with L-carnitine reduced the frequency of muscle cramps more effectively. Hypotension was significantly lower in combination therapy in comparison to baseline values and vitamin $\mathrm{E}$ treatment.

Conclusions:Vitamin E and L-carnitine both have comparative effects on intradialytic complications. As the combination use of vitamin E and L-carnitine could more effectively reduce the intradialytic complications, it is recommended for daily use in hemodialysis patients.

Keywords: Renal Dialysis; Kidney Failure, Chronic; Vitamin E; Carnitine

\section{Background}

The prevalence and incidence of chronic renal failure (CRF) is increasing all over the world, and this has become a serious problem. CRF is characterized by slow and progressive decline in the kidney function (1). Hemodialysis, a lifesaving procedure for advanced CRF patients, is associated with a number of acute intradialytic complications and symptoms such as hypotension, chest pain, back pain, muscle cramps, nausea, vomiting, headache, pruritus and fatigue (2-4).

Intradialytic hypotension is a common complication with associated symptoms such as nausea, vomiting, dizziness and cramps. Intradialytic hypotension may cause premature discontinuation of hemodialysis that may lead to chronic underdialysis and higher mortality risks $(5,6)$. The other prevalent complication is muscle cramp which causes severe pain and interferes with normal life function (7-9).
Various treatments are proposed, amongst them vitamin E and L-carnitine supplementation are the most beneficiary ones. As vitamin E reduces oxidative stress, many studies have tested vitamin E supplementation as a therapy to prevent various chronic diseases. Vitamin $\mathrm{E}$ has been recommended as the initial treatment of choice for HD cramps $(10,11)$.

L-carnitine is a quaternary amine known to transfer long chain fatty acids from cytoplasm into the mitochondrial matrix to be oxidized (12). In humans, carnitine plays a pivotal role in energy metabolism (13). There is marked reduction in the production of carnitine in endstage renal disease (ESRD) patients, and is significantly reduced in hemodialysis patients $(14,15)$. Regular carnitine supplementation in hemodialysis patients may reduce the incidence of intradialytic muscle cramps, hypotension, asthenia, muscle weakness, and cardiomyopathy (16-19); however, its effects on dialysis-related muscle cramping or intradialytic hypotension are questioned by

Implication for health policy/practice/research/medical education:

Vitamin E and L-carnitine are both useful in reducing intradialytic complications. If used together, could more effectively reduce the intradialytic complications.

Copyright (C) 2013, Nephrology and Urology Research Center; Licensee Kowsar Ltd. This is an Open Access article distributed under the terms of the Creative Commons Attribution License (http://creativecommons.org/licenses/by/3.0), which permits unrestricted use, distribution, and reproduction in any medium, provided the original work is properly cited. 
another study(20).

\section{Objectives}

Although there are various reports considering vitamin $E$ and L-carnitine effects on intradialytic complications, there is no study comparing the effects of these two supplements. In this study we aim to evaluate that which treatment including vitamin E, L-carnitine alone or in combination has more beneficiary effects.

\section{Patients and Methods}

\subsection{Study Population}

In this prospective study, we evaluated the effect of Lcarnitine, vitamin E or their combination supplementation on intradialytic complications. For this purpose, 20 adult patients (11 male, 9 female with mean age of $51.35 \pm$ 12.90 years) who had been undergoing thrice-weekly HD treatments, each time for 4 hours for at least 1 year at 2 facilities (Sahid Madani hospital and Sina hospital) with an arteriovenous fistula as blood access and anuria with no renal function for a minimum of 1 year were included. The mean blood flow of $350 \mathrm{~mL} / \mathrm{min}$ and bicarbonate dialysate flow rate of $500 \mathrm{~mL} / \mathrm{min}$ were maintained during dialysis. All these patients had complaints about intradialytic complications in the 3 months preceding enrollment. Subjects who had cardiovascular disease with Class III and IV symptoms, as defined by the New York heart association criteria, were excluded. The ethics committee of Tabriz university of medical sciences approved the study, and all subjects gave informed consent.

\subsection{Study Design}

Patients were scheduled to receive various treatment protocols for 6 months. Patients were first evaluated for 45 days (10 dialysis sessions) without any treatment as baseline and their complications during dialysis were recorded (step 1). Then patients were given oral vitamin E supplementation (200 U/daily) for the next 45 days (step 2). For the next 45 days, vitamin E supplement was stopped and patients were given oral L-carnitine (500 $\mathrm{mg}$ /daily) (step 3). During the last 45 days, patients were given vitamin E supplementation (200 U/daily) and oral L-carnitine (500 mg/daily) together (step 4). During the study period, patients were advised to maintain their everyday diet, medication or daily activities. Those who could not keep up with the study protocol or with drug intolerance were excluded.

Any complications during dialysis including muscle cramp, pain and nausea and vomiting were recorded. The occurrence of painful muscle cramps was recorded. A muscle cramp was defined as a painful involuntary muscle contraction that lasted more than 1 min during the dialysis (7). Blood pressure was measured every $30 \mathrm{~min}$. An intradialytic hypotensive episode was a decrease of more than $15 \mathrm{mmHg}$ in either systolic or diastolic blood pressure.

\subsection{Statistical Analyses}

Statistical analyses were performed using the statistical package for social sciences, version 16.0 (SPSS, Chicago, Illinois). Continuous values were expressed as mean \pm standard deviation and categorical variables were expressed as percentages. The categorical parameters were compared by Chi-square tests or Fisher's exact test. A p value $<0.05$ was considered significant.

\section{Results}

Cause of ESRD was diabetes in 8 cases, glomerulopathy in 7 cases, tubular disease in 3 cases and with unknown etiology in 2 cases.

Patients' complications during dialysis are shown in Table 1. There was a significant difference in frequency of muscle cramps between steps, but the difference in other complications was not significant.

Muscle cramps: All three treatments significantly reduced frequency of muscle cramps in comparison to baseline values $(\mathrm{P}<0.001$ for vitamin $\mathrm{E}$ and vitamin $\mathrm{E}$ and L-carnitine combination; $\mathrm{P}=0.03$ for L-carnitine). The combination treatment (vitamin E and L-carnitine) had significantly higher reduction in frequency of muscle

Table 1. Intradialytic Complications in Different Treatment Protocols

\begin{tabular}{|c|c|c|c|c|c|}
\hline & $\begin{array}{l}\text { Step } 1 \text { (No Treat- } \\
\text { ment) }\end{array}$ & Step 2 (Vitamin E) & $\begin{array}{l}\text { Step } 3 \text { (L-Carni- } \\
\text { tine) }\end{array}$ & $\begin{array}{l}\text { Step } 4 \text { (Vitamin E } \\
\text { and L-Carnitine) }\end{array}$ & Pvalue \\
\hline $\begin{array}{l}\text { Frequency of muscle } \\
\text { cramp }\end{array}$ & $6.40 \pm 1.63$ & $3.85 \pm 1.42$ & $5.25 \pm 1.61$ & $3.15 \pm 0.93$ & $\mathrm{P}<0.001$ \\
\hline Hypotension, No.(\%) & $16(80)$ & $16(80)$ & $14(70)$ & $9(45)$ & 0.055 \\
\hline $\begin{array}{l}\text { Nausea and vomit- } \\
\text { ing, No.(\%) }\end{array}$ & $6(30 \%)$ & $5(25)$ & $5(25)$ & $4(20)$ & 0.91 \\
\hline $\begin{array}{l}\text { Chest and/or back } \\
\text { pain, No.(\%) }\end{array}$ & $5(25)$ & $4(20)$ & $4(20)$ & $4(20)$ & 0.97 \\
\hline Pruritus No.(\%) & $2(10)$ & $2(10)$ & $1(5)$ & $1(5)$ & 0.86 \\
\hline
\end{tabular}


cramps than L-carnitine $(\mathrm{P}<0.001)$, but the difference with vitamin $E$ alone was not significant $(P=0.07)$. Vitamin $\mathrm{E}$ in comparison to L-carnitine reduced more effectively the frequency of muscle cramps $(\mathrm{P}=0.006)$ (Table 1$)$.

Hypotension: In comparison to baseline findings, hypotension was significantly reduced with combined treatment (vitamin E and L-carnitine) $(\mathrm{P}=0.04)$, and not with vitamin E or L-carnitine alone. There was also significant reduction in combined treatment in comparison to patients receiving vitamin $\mathrm{E}(\mathrm{P}=0.04)$; but the difference between patients receiving L-carnitine and combined treatment was not significant $(\mathrm{P}>0.05)$ (Table 1).

Other complications: There was no significant reduction of neither nausea and vomiting, nor pain and pruritus by any of treatments $(P>0.05)$ (Table 1$)$. No supplement related adverse effects were encountered during the trial.

\section{Discussion}

Chronic Renal failure is a common public health problem, which occurs in many countries with an increasing prevalence. Hemodialysis, which is one of the renal replacement therapies, is a life-saving treatment. However, hemodialysis is accompanied by several complications. The most prevalent complications are muscle cramp and hypotension. Other common complications include nausea, vomiting, headache and pruritus (21-25). As these complications have adverse effects on the quality of life of the patients, there are efforts to reduce them and improve patients' quality of life.

Vitamin E and L-carnitine are the two supplements evaluated in this respect which have shown beneficiary effects. It seems that L-carnitine administration might be rational in hemodialysis patients as it may improve several situations, such as cardiac performance, as well as positive protein balance induction, insulin resistance reduction, and chronic inflammation amelioration (26).

We found no study evaluating the combination of these treatments. The combination of vitamin E and L-carnitine are studied in different studies and have shown better results in comparison to separate use of vitamin $\mathrm{E}$ and L-carnitine (27-29). In this study we evaluated the effect of vitamin $\mathrm{E}$ and L-carnitine alone and in combination in reducing intradialytic complications.

Muscle cramps are the most prevalent intradialytic complication and most studies have tried to introduce palliative treatments to it. We observed a significant reduction in frequency of muscle cramps in all three treatment protocols in comparison to baseline values. Vitamin E alone or in combination also had a more significant reduction in frequency of muscle cramps than L-carnitine supplement. El-Hennawy and Zaib (10) also reported reduction of cramps attack after vitamin $\mathrm{E}$ supplementation. The effects of L-carnitine on relieving muscle cramps are shown in various studies, as well (16,
17,19). Khajedehi and colleagues (30) also reported better results in patients receiving vitamin $\mathrm{E}$ and combination of vitamin $\mathrm{E}$ and vitamin $\mathrm{C}$ in reducing muscle cramps. Our results and Khajedehi and colleagues' (30) are indicative of better effects of vitamin $\mathrm{E}$ in combination therapy. Ahmad et al. (16) reported a reduction in hypotension rate in patients receiving L-carnitine. However, a metaanalysis by Lynch and colleagues (20) could not confirm a beneficial effect of L-carnitine supplementation on dialysis-related intradialytic hypotension. We found no study evaluating the effects of vitamin E supplementation on intradialytic hypotension, although it is shown that vitamin E-modified dialyzers could reduce hypotension (31). In this study we observed no beneficiary effect of vitamin E or L-carnitine alone on intradialytic hypotension. However, hypotension was significantly reduced with combined treatment of vitamin $\mathrm{E}$ and L-carnitine.

We found no significant reduction of neither nausea and vomiting, nor pain and pruritus by any of treatments; this could be due to the low frequency of these complications at the beginning of the study.

There is limited data on the efficacy of oral L-carnitine and the use of oral supplements due to its limited bioavailability, high doses of drug (32) and probable side effects of its toxic metabolites $(33,34)$ is not recommended. The reported usually used oral dose of L-carnitine in previous studies was 1000-3000 mg/d (35), unlike our study $(500 \mathrm{mg} / \mathrm{d})$. The lower effects of L-carnitine in reducing intradialytic complications could be due to lower dose of L-carnitine administered in our study. Similar to our findings, Debska-Slizien and colleagues (36) observed that L-carnitine in low doses $(500 \mathrm{mg} / \mathrm{d}$ ) can improve plasma total and free carnitine levels; this improvement subsequently could improve some markers, indicative of effectiveness of low dose L-carnitine supplementation. However, due to its better results in low dose in combination with vitamin E with no probable complications of its use, L-carnitine could be recommended for combination treatment of intradialytic symptoms.

Conclusion: Both vitamin E and L-carnitine supplements have good and comparative effects on improving intradialytic complications. The combination of vitamin E and L-carnitine combination was more effective than treatments alone and could more effectively reduce the intradialytic complications and so it is recommended for daily use in hemodialysis patients.

\section{Acknowledgements}

This research was financially supported by Vice Chancellor for Research, Tabriz University of Medical Sciences, Iran.

\section{Authors' Contribution}

We would like to express that all authors have significant contribution to the content of the manuscript and are in agreement with it. 


\section{Financial Disclosure}

There is no conflict of interest.

\section{Funding/Support}

This research was financially supported by Vice Chancellor for Research, Tabriz University of Medical Sciences.

\section{References}

1. Amparo M, Alicia M, Mariano L, Alfonso P, Rosa M. Evidence of increased susceptibility of lipid peroxidation in RBCs of CRF patients. Nephron. 1988;50:64-5.

2. Daugirdas JT. Dialysis hypotension: a hemodynamic analysis. Kidney Int. 1991;39(2):233-46.

3. Campese VM. Cardiovascular instability during hemodialysis. Kidney Int Suppl.1988;24:S186-90.

4. Canzanello VJ, Hylander-Rossner B, Sands RE, Morgan TM, Jordan J, Burkart JM. Comparison of 50\% dextrose water, 25\% mannitol, and $23.5 \%$ saline for the treatment of hemodialysis-associated muscle cramps. ASAIO Trans. 1991;37(4):649-52.

5. Palmer BF, Henrich WL. Recent advances in the prevention and management of intradialytic hypotension. J Am Soc Nephrol. 2008;19(1):8-11.

6. Tisler A, Akocsi K, Borbas B, Fazakas L, Ferenczi S, Gorogh S, et al. The effect of frequent or occasional dialysis-associated hypotension on survival of patients on maintenance haemodialysis. Nephrol Dial Transplant. 2003;18(12):2601-5.

7. Chou CT, Wasserstein A, Schumacher HR, Jr, Fernandez P. Musculoskeletal manifestations in hemodialysis patients. J Rheumatol. 1985;12(6):1149-53.

8. McGee SR. Muscle cramps. Arch Intern Med.1990;150(3):511-8.

9. Riley JD, Antony SJ. Leg cramps: differential diagnosis and management. Am Fam Physician. 1995;52(6):1794-8.

10. El-Hennawy AS, Zaib S. A selected controlled trial of supplementary vitamin $\mathrm{E}$ for treatment of muscle cramps in hemodialysis patients. Am J Ther. 2010;17(5):455-9.

11. Roca AO, Jarjoura D, Blend D, Cugino A, Rutecki GW, Nuchikat PS, et al. Dialysis leg cramps. Efficacy of quinine versus vitamin E. ASAIO J.1992;38(3):M481-5.

12. Spagnoli LG, Palmieri G, Mauriello A, Vacha GM, D'Iddio S, Giorcelli G, et al. Morphometric evidence of the trophic effect of Lcarnitine on human skeletal muscle. Nephron.1990;55(1):16-23.

13. Zammit VA. Carnitine acyltransferases: functional significance of subcellular distribution and membrane topology. Prog Lipid Res.1999;38(3):199-224.

14. de los Reyes B, Navarro JA, Perez-Garcia R, Liras A, Campos Y, Bornstein $B$, et al. Effects of L-carnitine on erythrocyte acyl-CoA, free $\mathrm{CoA}$, and glycerophospholipid acyltransferase in uremia. Am J Clin Nutr.1998;67(3):386-90.

15. Labonia WD. L-carnitine effects on anemia in hemodialyzed patients treated with erythropoietin. Am J Kidney Dis. 1995;26(5):757-64.

16. Ahmad S, Robertson HT, Golper TA, Wolfson M, Kurtin P, Katz LA, et al. Multicenter trial of L-carnitine in maintenance hemodialysis patients. II. Clinical and biochemical effects. Kidney Int. 1990;38(5):912-8.
17. Bellinghieri G, Santoro D, Calvani M, Mallamace A, Savica V. Carnitine and hemodialysis. Am J Kidney Dis. 2003;41(3 Suppl 1):S116-22.

18. Feinfeld DA, Kurian P, Cheng JT, Dilimetin G, Arriola MR, Ward L, et al. Effect of oral L-carnitine on serum myoglobin in hemodialysis patients. Ren Fail.1996;18(1):91-6.

19. Sakurauchi Y, Matsumoto Y, Shinzato T, Takai I, Nakamura Y, Sato $\mathrm{M}$, et al. Effects of L-carnitine supplementation on muscular symptoms in hemodialyzed patients. Am J Kidney Dis. 1998;32(2):258-64.

20. Lynch KE, Feldman HI, Berlin JA, Flory J, Rowan CG, Brunelli SM. Effects of L-carnitine on dialysis-related hypotension and muscle cramps: a meta-analysis. Am J Kidney Dis. 2008;52(5):962-71.

21. Cruz DN, Mahnensmith RL, Perazella MA. Intradialytic hypotension: is midodrine beneficial in symptomatic hemodialysis patients? Am J Kidney Dis. 1997;30(6):772-9.

22. Davenport A. Intradialytic complications during hemodialysis. Hemodial Int. 2006;10(2):162-7.

23. Jesus AC, Oliveira HA, Paixao MO, Fraga TP, Barreto FJ, Valenca MM. Clinical description of hemodialysis headache in end-stage renal disease patients. Arq Neuropsiquiatr. 2009;67(4):978-81.

24. Kobrin SM, Berns JS. Quinine--a tonic too bitter for hemodialysisassociated muscle cramps? Semin Dial. 2007;20(5):396-401.

25. Narita I, Iguchi S, Omori K, Gejyo F. Uremic pruritus in chronic hemodialysis patients.J Nephrol. 2008;21(2):161-5.

26. Rostami Z, Nemati E. L-Carnitine supplementation in uremic patients. Nephro-Urol Mon. 2011;3(3):209-210.

27. Dhitavat S, Ortiz D, Rogers E, Rivera E, Shea TB. Folate, vitamin E, and acetyl-L-carnitine provide synergistic protection against oxidative stress resulting from exposure of human neuroblastoma cells to amyloid-beta. Brain Res. 2005;1061(2):114-7.

28. Onem G, Aral E, Enli Y, Oguz EO, Coskun E, Aybek H, et al. Neuroprotective effects of L-carnitine and vitamin E alone or in combination against ischemia-reperfusion injury in rats. J Surg Res. 2006;131(1):124-30.

29. Safarinejad MR, Hosseini SY, Kolahi AA. Comparison of vitamin E and propionyl-L-carnitine, separately or in combination, in patients with early chronic Peyronie's disease: a double-blind, placebo controlled, randomized study. J Urol. 2007;178(4 Pt 1):1398-403.

30. Khajehdehi P, Mojerlou M, Behzadi S, Rais-Jalali GA. A randomized, double-blind, placebo-controlled trial of supplementary vitamins $\mathrm{E}, \mathrm{C}$ and their combination for treatment of haemodialysis cramps. Nephrol Dial Transplant. 2001;16(7):1448-51.

31. Tanimu D, Huraib S, Shaheen FA, Hejaili F, Giles C, Pagayon V. The Effect of Vitamin E-Modified Dialyzers on Acute Intra-dialytic Symptoms: A Comparative Crossover Study. Saudi J Kidney Dis Transpl. 2003;14(4):451-5.

32. Brass EP. Pharmacokinetic considerations for the therapeutic use of carnitine in hemodialysis patients. Clin Ther.1995;17(2):176-85.

33. Bain MA, Faull R, Milne RW, Evans AM. Oral L-carnitine: metabolite formation and hemodialysis. Curr Drug Metab. 2006;7(7):811-6.

34. Schreiber B. Safety of oral carnitine in dialysis patients. Semin Dial. 2002;15(1):71-2.

35. Hurot JM, Cucherat M, Haugh M, Fouque D. Effects of L-carnitine supplementation in maintenance hemodialysis patients: a systematic review. J Am Soc Nephrol. 2002;13(3):708-14.

36. Debska-Slizien A, Owczarzak A, Kunicka D, Krol E, Lysiak Szydlowska W, Rutkowski B. Erythrocyte metabolism and renal anemia in hemodialyzed patients supplemented with L-Carnitine. Int J Nephrol Urol. 2011;3(1):23-33. 